\title{
Inhibition of BMP4 and Alpha Smooth Muscle Actin Expression in LX-2 Hepatic Stellate Cells by BMP4-siRNA Lipid Based Nanoparticle
}

\author{
Refaat Omar ${ }^{1}$, Jiaqi Yang ${ }^{1}$, Samaa Alrushaid ${ }^{1}$, Frank J. Burczynski ${ }^{1,3}$, Gerald Y. Minuk ${ }^{1,2}$ and Yuewen Gong ${ }^{1,2}$ \\ ${ }^{1}$ College of Pharmacy, Rady Faculty of Health Sciences, ${ }^{2}$ Section of Hepatology, Department of Internal Medicine, Max \\ Rady College of Medicine, ${ }^{3}$ Department of Pharmacology \& Therapeutics, Max Rady College of Medicine, Rady Faculty of \\ Health Sciences, University of Manitoba, Winnipeg, MB, Canada.
}

Received, September 22, 2017; Revised, February 26, 2018; Accepted, March 21, 2018; Published, March 22, 2018.

\begin{abstract}
Purpose: To develop and characterize vitamin A (VA)-coupled liposomes for the targeted delivery of BMP4-siRNA to hepatic stellate cells (HSC). VA was selected to increase the uptake by HSC based on their function in the storage of VA. Methods: DOTAP/DOPE liposomes were prepared by film hydration method and their surfaces were decorated with VA. The cytotoxicity of VA-conjugated liposomes was evaluated by the WST1 assay. Inhibition of BMP4 and $\alpha$-SMA was determined by PCR and ELISA. Results: VA-coated lipoplexes exhibited an average particle sizes less than $200 \mathrm{~nm}$ and zeta potential around $+25 \mathrm{mV}$ both determined using ZetaPALS. Inclusion of VA to liposomal surfaces significantly enhanced their cellular uptake without affecting cytotoxicity. VA-coupled liposomes carrying BMP4-siRNA resulted in a significant reduction in BMP4 and $\alpha-$ SMA at both mRNA and protein levels. Conclusion: VA-coated liposomes were successfully designed to deliver BMP4-siRNA to specifically target HSC. The novel delivery system discussed herein may serve as a potential therapeutic strategy for the treatment of liver fibrosis in the future.
\end{abstract}

This article is open to POST-PUBLICATION REVIEW. Registered readers (see "For Readers") may comment by clicking on ABSTRACT on the issue's contents page.

\section{INTRODUCTION}

Liver fibrosis is a reversible response following liver injury (1). Although fibrosis is a natural compensatory mechanism to minimize liver injury, liver function is significantly impaired (2-4). Hepatic fibrosis is characterised by excessive accumulation and reduced degradation of extra cellular matrix (ECM). Accumulation of ECM alters the hepatic architecture by forming a fibrous scar and development of nodules that may lead to cirrhosis, portal hypertension and may even progress to liver failure $(5,6)$. In general, hepatic stellate cells (HSC) are the major player in the development of liver fibrosis as HSC are the main source of the excessive production of ECM in an injured liver $(7,8)$. When the liver is injured, HSC become activated and transform from quiescent (retinoid-rich phenotype) to myofibroblast-like phenotype, which produce larger amounts of ECM proteins, such as collagens type I, III and laminin as compared to quiescent HSC (9-11).

Among many profibrogenic cytokines, bone morphogenetic protein BMP4 appears to be involved in liver fibrinogenesis. Recent studies demonstrated that BMP2 and BMP4 increase the expression of alpha smooth muscle actin ( $\alpha$-SMA) in cultured HSC $(12,13)$. The expression of $\alpha$-SMA is a marker of HSC trans-differentiation and their transformation into myofibroblast-like phenotype (1). In addition, it has been shown that BMPs exhibit a potent effect on the regulation of HSC trans-differentiation (12). Moreover, BMP4 itself is over expressed in other liver diseases, such as bile duct ligated liver (13) and, in liver cancer(14, 15). Therefore, targeting HSC could be one an effective strategy for treatment of liver fibrosis (16).

The specific association between BMP4 and various liver diseases including liver fibrosis makes it an excellent target for drug delivery to HSC (1215). RNA interference (RNAi) is a new promising therapeutic approach in which a specific gene expression could be regulated using small interfering RNA (siRNA) sequence $(17,18)$. However, there are challenges associated with siRNA therapy with its

Corresponding Author: Yuewen Gong, Ph.D., B.M. Professor, College of Pharmacy, Rady Faculty of Health Sciences, University of Manitoba, 750 McDermot Avenue, Winnipeg, Manitoba, Canada; Email: Yuewen.Gong@umanitoba.ca 
systemic administration, including safety, stability and effective delivery to the target tissue (19). Therefore, the key to overcome these challenges and improve therapeutic outcomes to siRNA application lies on the development of safe and effective siRNAdelivery systems.

Biocompatible cationic liposomes are considered excellent vehicles for siRNA delivery (20). This is attributed to their ability to form lipoplexes with negatively charged siRNA via electrostatic interaction. In addition, they enhance binding to negatively charged biological membrane components facilitating the uptake of the liposomes by endocytosis (21-23). In the present study we utilized DOTAP/DOPE liposomes and modified their surfaces with vitamin A (VA) to specifically target HSC with BMP4-siRNA and examine their regulation of BMP4 expression in human hepatic stellate cell line culture (LX-2) for gene silencing and internalization. VA was chosen as a specific ligand based on the significant capacity of HSC for its uptake and storage via the retinol binding protein (RBP) receptor. VA -coupled liposomes have previously been shown to enhance cellular uptake of collagen specific chaperone (gp 46) siRNA to HSC. (24).

\section{MATERIALS and METHODS}

\section{Materials}

1,2-Dioleoyl-sn-Glycero-3-Phosphoethanolamine (DOPE) and 1,2-Dioleoyl-3-TrimethylammoniumPropane (DOTAP) were purchased from NOF, America Corporation (NY, USA). D-(+)-Trehalose dehydrate, VA and Dimethyl sulfoxide (DMSO) were purchased from Sigma Aldrich (ON, Canada). HPLC grade chloroform was obtained from Fisher Scientific (ON, Canada). Amicon ${ }^{\circledR}$ Ultra-4 centrifugal filters devices $(30,000$ NMWL) were from EMD Millipore (Massachusetts, USA). Premixed WST-1 cell proliferation reagent was purchased from Clontec (ON, Canada). Polymerase chain reaction (PCR) primers were designed by the Oligo 7 computer software and synthesized by Life Technologies (ON, Canada). PCR primer sequenes used are as follows: BMP4: forward: 5'ATGTGGGCTGGAATGACTGG -3', reverse: 5'GCACAATGGCATGGTTGGTT $-3^{\prime} ; \quad \alpha$-SMA: forward: 5'- GAGACCCTGTTCCAG CCA TC -3', reverse: 5'- TACATAGTGGTGCCCCCTGA -3'.
BMP4 qPCR Template Standard, $\alpha$-SMA qPCR Template Standard were obtained from OriGene Technologies (Maryland, USA). PureLink ${ }^{\circledR}$ RNA Mini Kit was from Life Technologies (ON, Canada). Halt Protease and Phosphatase Inhibitor Cocktail (100X) were purchased from Life Technology (ON, Canada). BCA Protein Assay Kit was purchased from Thermo Scientific (ON, Canada), The iScript cDNA Synthesis Kit was purchased from the BioRad Laboratories Ltd. (ON, Canada) and Power SYBR ${ }^{\circledR}$ Green PCR MASTER MIX was obtained from Life Technologies (ON, Canada). Human BMP4 ELISA kit was purchased from abcam (ON, Canada), Lipofectamine 3000 was supplied by Life Technology (ON, Canada). Human Alpha-Smooth muscle actin, Alpha-SMA ELISA Kit was obtained from Novatein Biosciences (Massachusetts, USA).

\section{SiRNAs}

Silencer ${ }^{\circledR}$ Negative Control siRNA, Silencer ${ }^{\circledR}$ FAMlabeled Negative Control siRNA and Pre-designed siRNA silencers selectively targeting human BMP4 were purchased from Life technologies (ON, Canada). The siRNA was composed of $21 \mathrm{bps}$ (MW $13 \mathrm{kDa}$ ) with sequences of sense and the anti-sense strands as follows: sense: AGAGUGCCGUCAUUCCGGATT, antisense: UCCGGAAUGACGGCACUCUTG.

\section{Cell culture}

Human hepatic stellate cell line (LX-2 cells) was purchased from Millipore Ltd (ON, Canada) and cultured in Dulbecco's Modified Eagle Medium (DMEM) containing high glucose supplemented with $10 \%$ fetal bovine serum (FBS), $1 \mathrm{X}$ penicillin/ streptomycin and $1 \mathrm{X}$ Glutamine at $37{ }^{\circ} \mathrm{C}$ in a humidified atmosphere of $5 \% \mathrm{CO}_{2}$ and $95 \%$ air.

\section{Preparation of liposomes}

Liposomes were prepared using the thin-film hydration method as described elsewhere (25) with some modifications. Briefly, cationic liposomes were prepared using a 1:1 molar ratio of DOTAP and DOPE. Lipids (containing $50 \mathrm{mg}$ DOTAP and $47 \mathrm{mg}$ DOPE) were dissolved in HPLC-grade chloroform in a round bottom flask. After mixing the lipids, the solvent was dried at $55^{\circ} \mathrm{C}$ using a rotary evaporator yielding a lipid film. The thin lipid film was thoroughly dried to remove any residual chloroform by placing the flask under high vacuum pump for 1 $\mathrm{hr}$. The resulting dried film was hydrated in double 
distilled water $\left(\mathrm{ddH}_{2} \mathrm{O}\right)$ to make a stock solution of $10 \mathrm{mg} / \mathrm{mL}$. The lipid dispersion was warmed and mixed using a rotatory evaporator in which the round bottom flask was spinning in a warm water bath without vacuum for $10 \mathrm{~min}$ at $50^{\circ} \mathrm{C}$ above the lipid transition temperature (gel liquid crystal transition temperature). Liposomes particle size was reduced by sonication for $80 \mathrm{sec}$ at $7 \mathrm{kHz}$.

\section{Conjugation of vitamin $A$ to liposomes and lyophilization}

To prepare (VA)-coupled liposomes, VA was first dissolved in a minimal volume of DMSO $(2.6 \% \mathrm{VA}$, weight/mL DMSO). VA was then mixed with the liposomal suspension at a molar ratio of $(2: 1)$ VA/lipids(24). The mixture was incubated overnight at $-20{ }^{\circ} \mathrm{C}$ for complete adsorption of VA on liposomal surfaces. Following overnight incubation, DMSO and the free fraction of VA were removed by ultrafiltration using Amicon Ultra-4 centrifugal filter devices $(30,000 \mathrm{NMWL})$ at 4,000 rpm for $20 \mathrm{~min}$ repeated three times (24). The resultant liposomes were reconstituted in $\mathrm{ddH}_{2} \mathrm{O}$ and stored in amber colored vials at $4{ }^{\circ} \mathrm{C}$ overnight. Liposomes were lyophilized to increase long-term storage stability and protect the phospholipids within liposomes from being hydrolyzed or oxidized(26, 27). However, lyophilization is associated with changes in physicochemical properties of liposomes as a result of damage and rupture of lipid bilayers that may be caused by the formation of ice crystals during freezing, particle aggregation after dehydration, and phase transition during rehydration(28-30).

To stabilize liposomes during lyophilization, lyoprotectants, such as carbohydrates were used to maintain transfection efficiency(29-31). Liposomes employed in the present study were lyophilized utilizing trehalose as lyo-protectant as described elsewhere (26). Firstly, trehalose was added to liposomes at a mass ratio of 1:10 liposomes/trehalose in $\mathrm{ddH}_{2} \mathrm{O}$ and vortexed for 15 seconds at $25{ }^{\circ} \mathrm{C}$ in amber colored vials. Liposomes were then frozen at $-80{ }^{\circ} \mathrm{C}$ for $8 \mathrm{hr}$ followed by lyophilization at $-50{ }^{\circ} \mathrm{C}$ under reduced pressure $0.310 \mathrm{mBar}$ for $24 \mathrm{hr}$ (Labconco freeze dryer; Labconco Corp., MO, USA). The lyophilized samples were stored at -20 ${ }^{\circ} \mathrm{C}$ in amber colored vials for further characterization and siRNA loading.

\section{Preparation of Lipoplexes (siRNA-liposomes complex)}

Lyophilized samples were reconstituted in prewarmed $\mathrm{ddH} 2 \mathrm{O}$ to their original volume. The reconstituted liposomes were warmed in a water bath at $50{ }^{\circ} \mathrm{C}$ and mixed using a vortex mixer until the samples were totally dispersed (without any visually inspected particulate matter). To prepare lipoplexes, VA-liposomes were first prepared as mentioned above, and siRNA was diluted to a concentration of $1.0 \mu \mathrm{g} / \mu \mathrm{L}$ in nuclease-free water prior to lipoplex preparation. Lipoplexes were prepared by the addition of VA-liposomes to siRNA solution at various VA-liposomes /siRNA molar ratios of (10:1, 10:2 and 10:3 mol:mol). The mixture was gently mixed by pipetting up and down several times and then incubated at RT for 30 min to allow complex formation (32).

\section{Measurement of particle size and Zeta potential} Liposomes and lipoplexes were suspended in deionized water at $100-200 \mu \mathrm{g} / \mathrm{mL}$ of NP suspension, $\mathrm{pH}$ 7.4. The average size, polydispersity (particle size distribution) and zeta potential of VA-coupled liposome, VA-lipoplexes, VA-free liposomes and VA-free lipoplexes were determined at $25{ }^{\circ} \mathrm{C}$ by dynamic light scattering (DLS) using ZetaPALS (Brookhaven Instruments, Holtsville, NY, USA). Each sample was run for two min three times and all samples were tested in triplicates.

\section{SiRNA binding efficiency (BE)}

To measure siRNA-binding efficiency (BE), lipoplexes were prepared with FAM-labeled siRNA. The siRNA BE was determined by comparing the amount of initially added siRNA with the unencapsulated siRNA in the sample using ultracentrifugation and a fluorescence assay (33). Briefly, the lipoplexes were prepared by adding different concentrations $(1,3,5,9 \mu \mathrm{g} / \mathrm{mL})$ of fluorescein amidite (FAM)-labeled siRNA to a fixed volume $(3 \mu \mathrm{L})$ of VA-liposomes $(10 \mathrm{mg} / \mathrm{mL})$ to achieve a final liposomal concentration of $30 \mu \mathrm{g} / \mathrm{mL}(24,34)$. Lipoplexes were filtered using Amicon ${ }^{\circledR}$ Ultra-4 centrifugal filter devices $(30,000 \mathrm{M} . \mathrm{W}$. cut-off) at $4,000 \mathrm{rpm}$ for $15 \mathrm{~min}$. Following filtration, the filtrate containing the free fraction of FAM-siRNA was collected and quantified using a calibration curve obtained by serial dilution of standard FAMsiRNA solutions. The fluorescence intensity of FAM-siRNA was determined using a microplate 
reader (Synergy 4, Biotek, Wi, USA) at excitation and emission wavelengths of 495 and $525 \mathrm{~nm}$, respectively. The siRNA BE was calculated using the following formula:

$\mathrm{BE}=$

$$
\mathrm{BE}=\frac{\begin{array}{c}
\text { Initially added siRNA }- \\
\text { mass of unencapsulated siRNA }
\end{array}}{\text { Initially added siRNA }} \text { X100 }
$$

\section{Vitamin A Assay}

VA concentration was determined by Reverse Phase High-Performance Liquid Chromatography (RPHPLC) as describe earlier (35). Briefly, the free fraction of VA was removed by ultra-centrifugation of VA-liposomes 3 times using Amicon ${ }^{\circledR}$ Ultra-4 centrifugal filter devices $(30,000 \mathrm{NMWL})$ at 4,000 $\mathrm{rpm}$ for $20 \mathrm{~min}$ each (24). Liposomes $(500 \mu \mathrm{L})$ with a final lipid concentration of $10 \mathrm{mg} / \mathrm{mL}$ were dissolved in an equal volume of HPLC grade methanol in amber vials. Methanol was used for sample extraction and standard preparation. Retinol was used as internal standard. A stock solution of the standard was prepared by dissolving $4 \mathrm{mg}$ retinol in $1 \mathrm{~mL}$ HPLC grade methanol $(4 \mu \mathrm{g} / \mu \mathrm{L})$. Working solutions of the standard were prepared by serial dilution using HPLC grade methanol. Samples and standards were prepared in the dark and kept in amber color vials due to the light-sensitive nature of retinol. Aliquots of samples and the diluted standard solutions were transferred into small HPLC amber vials. A volume of $20 \mu \mathrm{L}$ of all the samples and standards was injected into the column. VA analysis was carried out using HPLC with UV detection (Waters Corp, USA). The separation of VA was carried out using Nova-Pak ${ }^{\circledR} \mathrm{C} 184 \mu \mathrm{m}$ particle size $3.9 \mathrm{X} 150 \mathrm{~mm}$ column with a mobile phase composed of acetonitrile, tetrahydrofuran and water $(55: 37: 8)$ respectively, at a flow rate of $1.2 \mathrm{~mL} / \mathrm{min}$. Detection was performed at $325 \mathrm{~nm}$. To avoid peaks from interfering with lipids, VA-free liposomes were used as a negative control. Standard curves for retinol were constructed using quality control concentrations of $62.5,125,250,500$ and 1000 $\mu \mathrm{g} / \mathrm{mL}$. Concentration of VA was measured using the equation of the standard curve, which established by plotting the amount of each standard dilution against the corresponding peak area.

\section{WST-1 Assay}

Cytotoxicity of the VA-coupled liposome was evaluated using a premixed WST-1 cell proliferation reagent (according to the manufacturer's protocol).
Briefly, LX-2 cells were seeded onto 96-well plates at a density of $1 \times 10^{4}$ cells per well in $100 \mu \mathrm{L}$ of DMEM media and incubated for $24 \mathrm{hr}$. The following day, cell culture media was replaced with Opti-MEM $^{\circledR}$ reduced serum medium. A volume of $10 \mu \mathrm{L}$ of VA free liposomes and VA-coupled liposome was added to each well, to achieve a final concentration of 25 to $250 \mu \mathrm{g} / \mathrm{mL}$ per well. Afterwards, the plate was incubated for an additional $24 \mathrm{hr}$. Blank cell media was used as negative controls while untreated cells were used as positive controls. Cell proliferation was evaluated by adding $10 \mu \mathrm{L}$ of WST-1 solution to each well and incubated at $37{ }^{\circ} \mathrm{C}$ for $2 \mathrm{hr}$. All concentrations were measured in triplicates. The absorbance was measured using a microplate reader (Synergy 4, Biotek, Wi, USA) at $540 \mathrm{~nm}$. Cell viability was calculated according to the following formula:

$$
\text { Cell viability } \%=\frac{\begin{array}{c}
\text { Absorbance of treated cells }- \\
\text { Absorbance of Blank }
\end{array}}{\begin{array}{c}
\text { Absorbance of control }- \\
\text { Absorbance of Blank }
\end{array}} \text { X100 }
$$

\section{in vitro cellular uptake}

LX-2 cells were seeded on 6-well plates at a density of $2 \times 10^{5}$ cells per well. After $24 \mathrm{hr}$ of incubation, the culture medium was exchanged with OptiMEM $^{\circledR}$ reduced serum medium. Cells were treated with $15 \mu \mathrm{g}$ liposomes containing $3 \mu \mathrm{g}$ FAM-labeled siRNA per well in $2 \mathrm{~mL}$ of the culture media and incubated for $4 \mathrm{hr}$. Cell medium was then removed by aspiration and cells were washed twice with PBS. Cells were detached by trypsinization. The resulting cell suspensions were centrifuged at $600 \mathrm{rpm}$ for 5 min and washed three times with 1 X PBS to remove any free FAM-labeled nanoparticles. Pellets were resuspended in $500 \mu \mathrm{L}$ PBS and the fluorescence intensity was measured by Flow Cytometer (BD Biosciences, San Hose, CA, USA) (32). Approximately $1 \times 10^{4}$ cells were counted by the flow cytometer determining the trend of the VAliposomes-siRNA extracted by the LX-2 cells. The instrument was calibrated using non-treated cells $(36,37)$. The Flow Cytometry data were analyzed using CELLQUEST v.1.0 software.

Intracellular delivery of siRNA to LX-2 cells was evaluated using a microplate reader. Briefly, LX-2 cells were seeded on 24-well plates at density of $5 \times 10^{4}$ cells per well $20 \mathrm{hr}$ before experiments. Cells were treated with different liposome formulations containing $2 \mu \mathrm{g} /$ well FAM-siRNA in 
the culture medium at $37{ }^{\circ} \mathrm{C}$ for $4 \mathrm{hr}$. Cells were washed three times with PBS followed by incubation with $300 \mu \mathrm{L}$ lysis buffer (0.3\% Triton X-100 in PBS) at RT for $30 \mathrm{~min}$. The fluorescence intensity of a 100 $\mu \mathrm{L}$ cell lysate was determined using a microplate reader (Synergy 4, Biotek, Wi, USA) at excitation and emission wavelengths of 495 and $525 \mathrm{~nm}$, respectively.

\section{SiRNA Transfection}

LX-2 cells were pre-seeded in 12-well plates at a density of $1 \times 10^{5}$ cells per well and incubated at $37^{\circ} \mathrm{C}$ for $12 \mathrm{hr}$ before experiments. Cells were treated with different formulations carrying $3 \mu \mathrm{g}$ of BMP4siRNA per well in $1 \mathrm{~mL}$ of Opti-MEM reduced serum medium. BMP4-siRNA was transfected into LX-2 cells using VA-coupled liposomes, VA-free liposomes and the commercial transfection agent Lipofectamine 3000. The second group was the control group including LX-2 cells treated with VAcoupled liposomes carrying negative control siRNA and normal control (non-transfected cells). LX-2 cells were incubated with BMP4-siRNA at $37^{\circ} \mathrm{C}$ for different time points $(24 \mathrm{hr}, 48 \mathrm{hr}$ and $72 \mathrm{hr}$ ).

\section{Gene Expression Analysis by RT-PCR}

Total RNA was extracted from cultured LX-2 cells using PureLink RNA Mini Kit according to the manufacturer's protocol. RNA purity and concentration were determined by Thermo Scientific NanoDrop 2000/2000c Spectrophotometers. Total RNA was converted to cDNA using iScript cDNA Synthesis Kit. The obtained cDNA was diluted to a concentration of $5 \mathrm{ng} / \mu \mathrm{L}$. Real time PCR (qPCR) was carried out for BMP4 and $\alpha$-SMA using the oligonucleotides synthesized by Invitrogen. The specific primers of each gene were designed based on the respective sequences obtained from GenBank by Oligo 7 program. Total reaction volume was 20 $\mu \mathrm{L}$ with $5 \mu \mathrm{L}$ of cDNA, $10 \mathrm{~mL}$ of $2 \mathrm{X}$ of Power SYBR $^{\circledR}$ Green PCR MASTER MIX and $0.5 \mu \mathrm{L}$ of 10 $\mu \mathrm{M}$ forward and reverse primers. qPCR amplification was achieved by running $10 \mathrm{~min}$ at $95^{\circ} \mathrm{C}$ for pre-denaturation and 50 cycles under the following cycle conditions: $30 \mathrm{sec}$ at $95^{\circ} \mathrm{C}$ for denaturation; different annealing temperatures for 1 min; elongation at $72^{\circ} \mathrm{C}$ for $2 \mathrm{~min}$; followed by a final elongation at $72^{\circ} \mathrm{C}$ for 10 min using a PCR Detection System (the Bio-Rad Laboratories, ON, Canada). Data were analyzed by Bio-Rad CFX Manager software version 3.1. The standard curve was established by plotting the log of the starting quantity of each template dilution against the respective fluorescence intensity acquired during the amplification known as $\mathrm{Ct}$ (cycle threshold) of each dilution. Concentrations of unknown samples were calculated based on the standard curve equation as follow:

Sample $($ number of copies $)=$

$$
\text { Ct sample - Intercept/slope }
$$

The comparative $\Delta \mathrm{Ct}$ method was applied to determine the change in gene expression between treated samples relative to control group. To examine regulation of BMP-4 or $\alpha$-SMA, the $\mathrm{Ct}$ from each treated sample was subtracted from the controltreated sample cycle values $(\Delta \mathrm{Ct}=\mathrm{Ct}$ control-Ct treated). The fold change of the test gene was determined as $2-\Delta \mathrm{Ct}$.

\section{Protein Isolation and Quantification}

Control and treated cells were grown in 6-well plates as mentioned above. Cells were washed with icecold PBS, trypsinized, and centrifuged at $600 \mathrm{rpm}$ for 5 min. Supernatant was discarded and the cell pellet was lysed in $100 \mu \mathrm{L}$ ice-cold protein extraction solution $(1 \times=50 \mathrm{mM}$ Tris, $\mathrm{pH} 8.0,0.5 \mathrm{mM}$ EDTA, $150 \mathrm{mM} \mathrm{NaCl}, 0.5 \% \mathrm{NP}-40)$ containing $1 \times$ protease inhibitor cocktail $(10 \mu \mathrm{L} / \mathrm{mL}$ lysis buffer: protease inhibitor). Cell lysates were maintained at constant agitation for 30 minutes at $4{ }^{\circ} \mathrm{C}$. Samples were centrifuged at $13,000 \mathrm{~g}$ for $15 \mathrm{~min}$ at $4{ }^{\circ} \mathrm{C}$. The supernatant of each sample was carefully collected and transferred into a new tube. Protein concentration was determined by the BCA protein assay.

\section{ELISA (Enzyme-Linked Immunosorbent Assay) method for detection of BMP4 and $\alpha$-SMA}

Following total protein isolation and quantification, ELISA was established to determine the concentration of BMP-4 and $\alpha$-SMA in cell lysates according to the manufacturer's instruction. The specific protein concentration of tested samples was determined based on the equation acquired by the respective standard curve. The standard curve was established by plotting the concentration of each standard dilution against the respective absorbance intensity. The absorbance was measured immediately at $450 \mathrm{~nm}$ using a microplate reader (Synergy 4, Biotek, WI, USA). 


\section{STATISTICAL ANALYSIS}

Data were analyzed using Prism 6.0 (Graph-Pad Software Inc.). Results were expressed as mean \pm standard deviation (SD) of $n \geq 3$ unless otherwise specified. One and two-way analysis of variance (ANOVA) tests were used to test significant differences between treatments with $p$-values $<0.05$ considered significant, $<0.01$ very significant, $<$ 0.001 highly significant and $<0.0001$ very highly significant.

\section{RESULTS}

\section{Characterization of Liposomes and Lipoplexes}

The average particle size of VA-free liposomes and VA-coupled liposomes ranged between 100 and 120 $\mathrm{nm}$ with a polydispersity index (PDI) around 0.20 (Table 1). The average zeta potential measurement for VA-free liposomes and VA-coupled liposomes in $\mathrm{ddH}_{2} \mathrm{O}(\mathrm{pH}$ 7.4) remained nearly constant at $\sim 45$ $\mathrm{mV}$. The addition of VA did not cause any significant change in terms of particle size, zeta potential and PDI of either liposome or lipoplexes. When liposomes were conjugated with siRNA to form lipoplexes, the average size and PDI were considerately increased. The measured zeta potential of the resulting lipoplexes, however, was not significantly decreased and ranged approximately between $45-25 \mathrm{mV}$.

SiRNA binding efficiency (BE) determined by ultra-filtration method and fluorescence assay is shown in Figure 1. The amount of unbound-siRNA was measured in the clear filtrate. The BE of VAcoupled liposomes prepared with FAM-labeled siRNA of varying concentrations $1,3,5$ and $9 \mu \mathrm{g} / \mathrm{mL}$ resulted in $\mathrm{BE} \%$ of $95.3 \pm 1.23,93.76 \pm 3.064,93.75$ $\pm 3.58,92.68 \pm 8.75$, respectively.

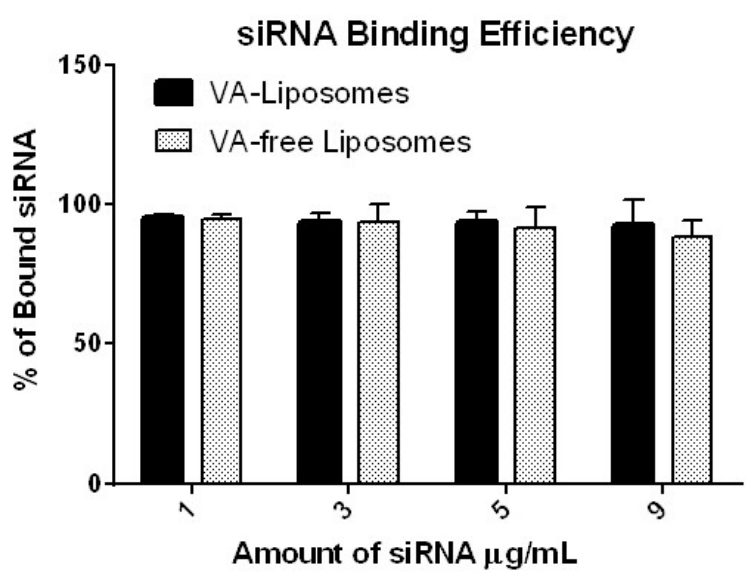

Figure 1. The binding efficiency of siRNA was assessed using a fixed concentration of the liposomal formulation $(30 \mu \mathrm{g} / \mathrm{mL})$ containing various concentrations of siRNA namely $1,3,5,9 \mu \mathrm{g} / \mathrm{mL}$ determined by the ultra-filtration method. The free fractions of siRNA in different samples were collected after ultra-filtration and then measured by a fluorescence assay. The results represent mean \pm $\mathrm{SD}(\mathrm{n}=3)$.

Similarly, the BE of VA-free liposomes was found to be $94.62 \pm 1.72,93.501 \pm 6.250,91.62 \pm$ $7.159,88.195 \pm 5.89$ at siRNA concentration of 1,3 , 5 , and $9 \mu \mathrm{g} / \mathrm{mL}$, respectively. There was no significant difference of siRNA BE either between VA-liposomes and VA-free liposomes, or in different concentrations.

HPLC was used to measure the concentration of VA that was loaded onto the liposomal formulation. Separation of VA in liposomes was successfully achieved isocratically using a mobile phase of

Table 1. The average particle size, zeta potential and polydispersity index (PDI) of liposomes and lipoplexes measured by dynamic light scattering using ZetaPALS.

\begin{tabular}{llll}
\hline LIPOSOMES FORMULATION & $\begin{array}{l}\text { PARTICLE } \\
\text { SIZE }(\mathbf{n m})\end{array}$ & ZETA POTENTIAL (mV) & POLYDISPERITY Index (PDI) \\
\hline VA-free liposomes $^{1}$ & $112.5 \pm 6.6$ & $46.25 \pm 7.7$ & $0.21475 \pm 0.034$ \\
VA-liposomes $^{2}$ & $113.5 \pm 5$ & $43.75 \pm 6.99$ & $0.20775 \pm 0.022$ \\
VA-free-siRNA lipoplexes $^{3}$ & $153.5 \pm 8$ & $27 \pm 3.65$ & $0.15 \pm 0.0139$ \\
VA-siRNA lipoplexes & \\
\hline Data represent means \pm SD; $\mathrm{n}=3$. T-Test: Particle size, 1 vs. $3: p<0.001,2$ vs. $4: p<0.001 ;$ PDI, 1 vs. $3: p<0.05,2$ vs. $4:$ \\
$p<0.01$.
\end{tabular}


acetonitrile-tetrahydrofuran-water $(55: 37: 8)$ at flow rate of $1.2 \mathrm{~mL} / \mathrm{min}$. Chromatograms showed no interfering peaks that co-eluted with our compound of interest at a retention time of $1.3 \mathrm{~min}$ for VA (Sup Figure 1). HPLC analysis showed that our liposomes contained $3.25 \mathrm{mg}$ VA per $\mathrm{mL}$, which makes up approximately $80 \%$ of the initially added amount of VA.

\section{Liposomes Toxicity Study}

To examine the biocompatibility of the liposomal formulation and its cytotoxicity, various concentrations of VA-coupled liposomes and VAfree liposomes were tested in LX-2 cells using the WST-1 assay (Figure 2). The data showed no significant difference between the cytotoxicity of VA-liposomes versus VA-free liposomes on LX-2 cells. Both VA-coupled liposomes and VA-free liposomes at concentrations up to $100 \mu \mathrm{g} / \mathrm{mL}$ were not toxic to LX-2 cells (cell viability 100\%) as illustrated in Figure 2. However, a significant reduction in cell viability $\sim 80 \%(\mathrm{p}<0.05)$ was observed with both liposomes at $150 \mu \mathrm{g} / \mathrm{mL}$. The highest tested toxic concentrations of VA-coupled liposomes was at $250 \mu \mathrm{g} / \mathrm{mL}$, which reduced the percentage of cell viability to $45.34 \%(\mathrm{p}<0.0001)$. At a concentration of $200 \mu \mathrm{g} / \mathrm{mL}$ the cell viability has decreased to $57.16 \%(\mathrm{p}<0.0001)$. Similar toxic effect was observed with VA-free liposomes at 200 and $250 \mu \mathrm{g} / \mathrm{mL}$ with $\sim 60 \%$ viable cell $(\mathrm{p}<0.0001)$ at both concentrations. Despite the concern about VA toxicity, the chosen concentration (50 to 100 $\mu \mathrm{g} / \mathrm{mL}$ ) of VA conjugated to liposomes was not cytotoxic.

\section{Cellular Uptake Study}

The delivery efficiency of VA-liposomes containing FAM-siRNA was evaluated in LX-2 cells using flow cytometry. Analysis of flow cytometry data showed that VA- liposomes possessed significantly higher internalization compared with VA free liposomes. LX-2 cells transfected with VA liposomes were $55 \pm$ $7 \%(\mathrm{p}<0.01)$ FAM-positive, whereas those transfected with VA-free liposomes were $30 \pm 9 \%$ (p $<0.05)$ FAM positive. However, treatment with naked siRNA did not induce any fluorescence (Figure 3).

The internalization of liposomes determined by measuring the fluorescence intensity using a microplate reader also showed that cells treated with VA-liposomes $(p<0.001)$ had significantly higher fluorescence intensities than those treated with VAfree liposomes $(p<0.05)$. The mean fluorescence intensity was $1592.3 \pm 238.7$ for VA-free liposomes treated cells and $2876.3 \pm 320.75$ for VA-coated liposomes treated cells (Figure 4).

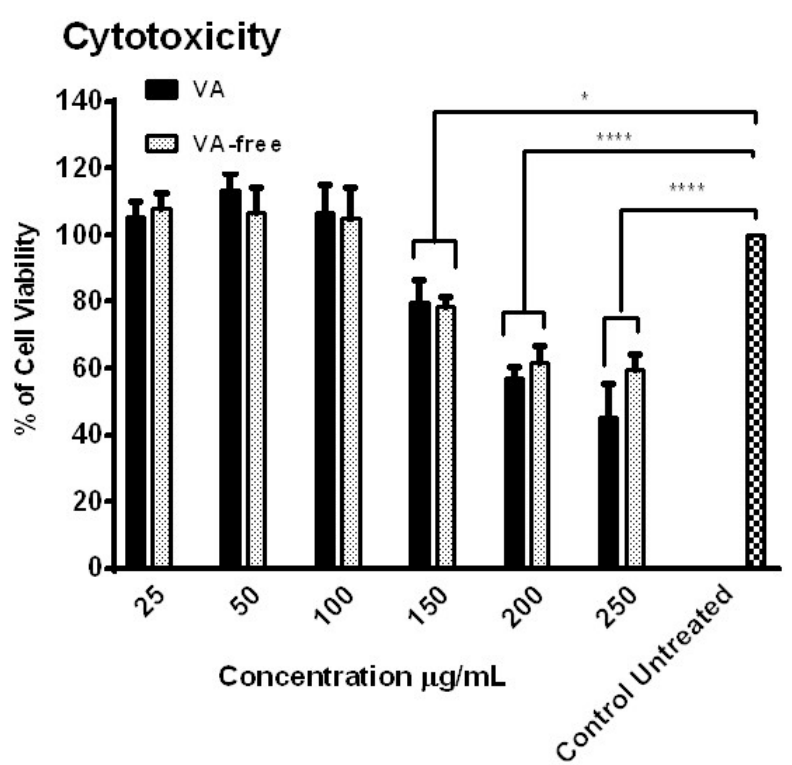

Figure 2. Cytotoxicity analysis determined by WST1 assay on LX-2 cells. The data show percentage of viable LX-2 cells after treatment with various concentrations of VA-coupled and VA-free liposomes namely $25,50,100,150,200$, and 250 $\mu \mathrm{g} / \mathrm{ml}$ in comparison with untreated cells at $24 \mathrm{~h}$ post-transfection using the WST-1 assay. The data shown represents three different experiments (each performed in triplicate) and are expressed as mean \pm SD. $(\mathrm{n}=3) .{ }^{*}=\mathrm{p}$-values $<0.05$ considered significant and $* * *=p<0.001$ highly significant.

The internalization of liposomes determined by measuring the fluorescence intensity using a microplate reader also showed that cells treated with VA-liposomes $(p<0.001)$ had significantly higher fluorescence intensities than those treated with VAfree liposomes $(\mathrm{p}<0.05)$. The mean fluorescence intensity was $1592.3 \pm 238.7$ for VA-free liposomes treated cells and $2876.3 \pm 320.75$ for VA-coated liposomes treated cells (Figure 4).

\section{In Vitro BMP4 Gene Silencing}

RT-PCR was used to examine the effect of BMP4siRNA on BMP4 gene expression. RT-PCR analysis showed that there was significant silencing of BMP4 gene $(>50 \%)$ after treatment with BMP4-siRNA at all-time points (Figure 5). The gene silencing 

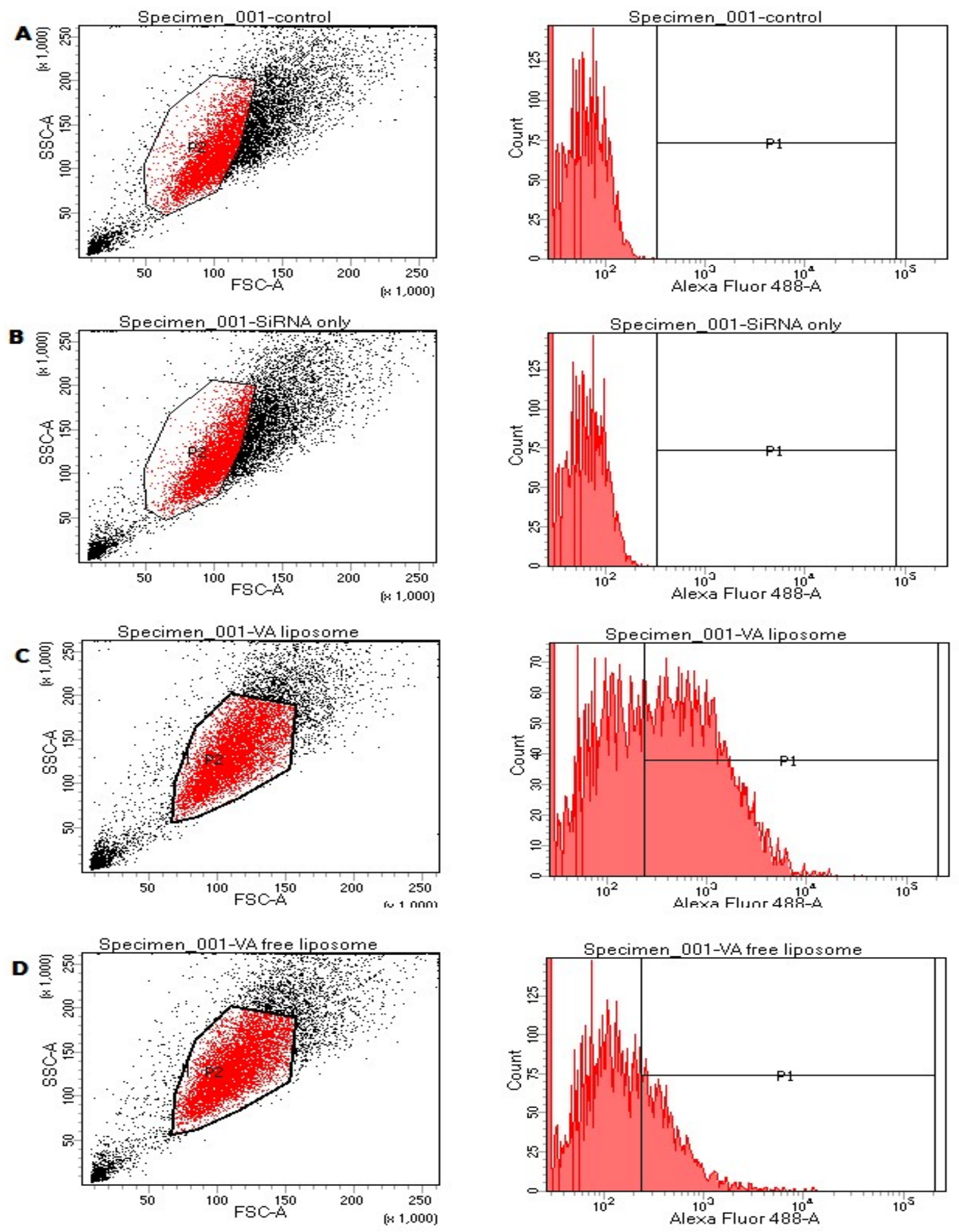

Figure 3. Flow cytometer analysis of $300 \mathrm{nM}$ FAM-labeled siRNA complexed to the liposomal formulation transfected into LX-2 cells after $4 \mathrm{~h}$ incubation. (A) Untreated cells (B) free siRNA as negative control (C) VA-liposome/siRNA (D) VA-free liposomes/siRNA. 
efficiency of BMP4-siRNA/VA-liposomes at $24 \mathrm{~h}$, $48 \mathrm{~h}$ and $72 \mathrm{~h}$ post transfection was $72.0 \pm 11.6 \%$ ( $p$ $<0.0001), 74.5 \pm 3.2 \%(p<0.0001)$, and $81.1 \pm 5.4$ $\%(p<0.0001)$, respectively. In addition, BMP4 expression was also significantly inhibited by BMP4-siRNA/VA free liposomes lipoplexes with \% inhibition of $60.6 \pm 6.4 \%(p<0.0001), 54.6 \pm 7.4 \%$ $(p<0.0001)$, and $55.7 \pm 6.7 \%(p<0.0001)$, at 24 , 48 and $72 \mathrm{~h}$ respectively. Similarly, after treatment with BMP4-siRNA/lipofectamine complex at alltime points, the BMP4 level was reduced to $46.0 \pm$ $5.6 \%(p<0.0001), 51.1 \pm 5.2 \%(p<0.0001)$, and $40.6 \pm 9.7 \%(p<0.0001)$ compared to untreated control. VA liposomes exhibit significantly lower mRNA expression level compared to VA-free liposomes after 48 and $72 \mathrm{hr}$ treatments. Therefore, BMP4-siRNA/VA-liposomes had the highest efficiency to inhibit BMP4 expression in LX-2 cells.

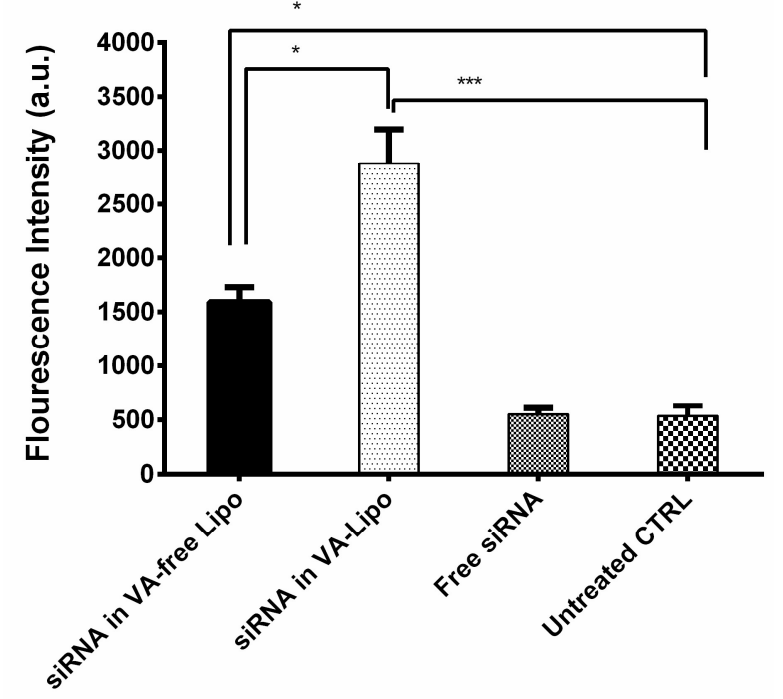

Figure 4. In vitro cellular uptake analysis determined by a microplate reader. The fluorescence intensities of cell lysates from LX-2 cells treated with FAM-siRNA represent the intracellular delivery efficiency for siRNA by a given formulation. Each value represents the mean \pm S.D. $(\mathrm{n}=3) .{ }^{*}=p$-values $<0.05$ considered significant and $* * *=p<0.001$ highly significant.

\section{Effect of BMP4 Gene Silencing on $\alpha$-SMA mRNA Expression}

BMP4 is the key cytokine that can increase the expression of $\alpha$-SMA in cultured HSC $(12,13)$.
Therefore, we measured $\alpha$-SMA mRNA expression in HSC cells after transfection with BMP4-siRNA (Figure 6). We observed that the treatment with BMP4-siRNA caused a significant reduction of $\alpha$ SMA expression in a similar manner as observed in the case of BMP4. All groups treated with VAliposomes, VA-free liposomes and Lipofectamine3000 carrying BMP4-siRNA caused significant $\alpha-$ SMA knockdown at all-time points. The $\alpha$-SMA expression in the group treated with BMP4-siRNA bound to VA-liposomes was $[22.8 \pm 3.3 \%(p<$ $0.0001), 36.0 \pm 5.7 \%(\mathrm{p}<0.0001)$, and $34.4 \pm 8.3 \%$ $(\mathrm{p}<0.0001)$ at $24 \mathrm{~h}, 48 \mathrm{~h}$ and $72 \mathrm{~h}$ respectively]. BMP4-siRNA delivered by VA-free liposomes and lipofectamine 3000 showed similar expression of $\alpha$ SMA compared with that of untreated control at alltime points [VA-free liposomes $=32.7 \pm 8.8 \%, 39.2$ $\pm 13.0 \%$ and $36.3 \pm 12.6 \%(p<0.0001)$ while, lipofectamine $3000=30.0 \pm 2.8 \%, 43.5 \pm 11.1 \%$ and $41.4 \pm 16.1 \%$ at $24 \mathrm{~h}, 48 \mathrm{~h}$ and $72 \mathrm{~h}$, respectively $(p<0.0001)]$.

\section{BMP4 protein expression analysis by ELISA}

The data obtained from ELISA showed that VAliposomes, VA-free liposomes, and lipofectamine 3000 caused significant reduction in BMP4 protein level at $48 \mathrm{~h}$ and $72 \mathrm{~h}$ (Figure 7). At $48 \mathrm{~h}$ post BMP4siRNA transfection, the expression level of BMP4 was significantly reduced to $52.8 \pm 4.6 \%(p<$ $0.0001), 63.7 \pm 4.3 \%(p<0.0001)$ and $50.6 \pm 4.0 \%$ $(p<0.0001)$ following treatment with VAliposomes, VA-free liposomes and Lipofectamine 3000, respectively, compared to untransfected control. Similarly, at $72 \mathrm{~h}$ post transfection, VAliposomes, VA-free liposomes and Lipofectamine 3000 showed significant suppression of BMP4 by $47.0 \pm 3.3 \%(p<0.0001), 44.0 \pm 5.1 \%(p<0.0001)$ and $50.1 \pm 5.2 \%(p<0.0001)$, respectively. However, at $24 \mathrm{~h}$ post transfection, only BMP4siRNA with Lipofectamine 3000 showed a significant knock down of BMP4 expression by nearly $36.9 \pm 3.8 \%(p<0.0001)$. 


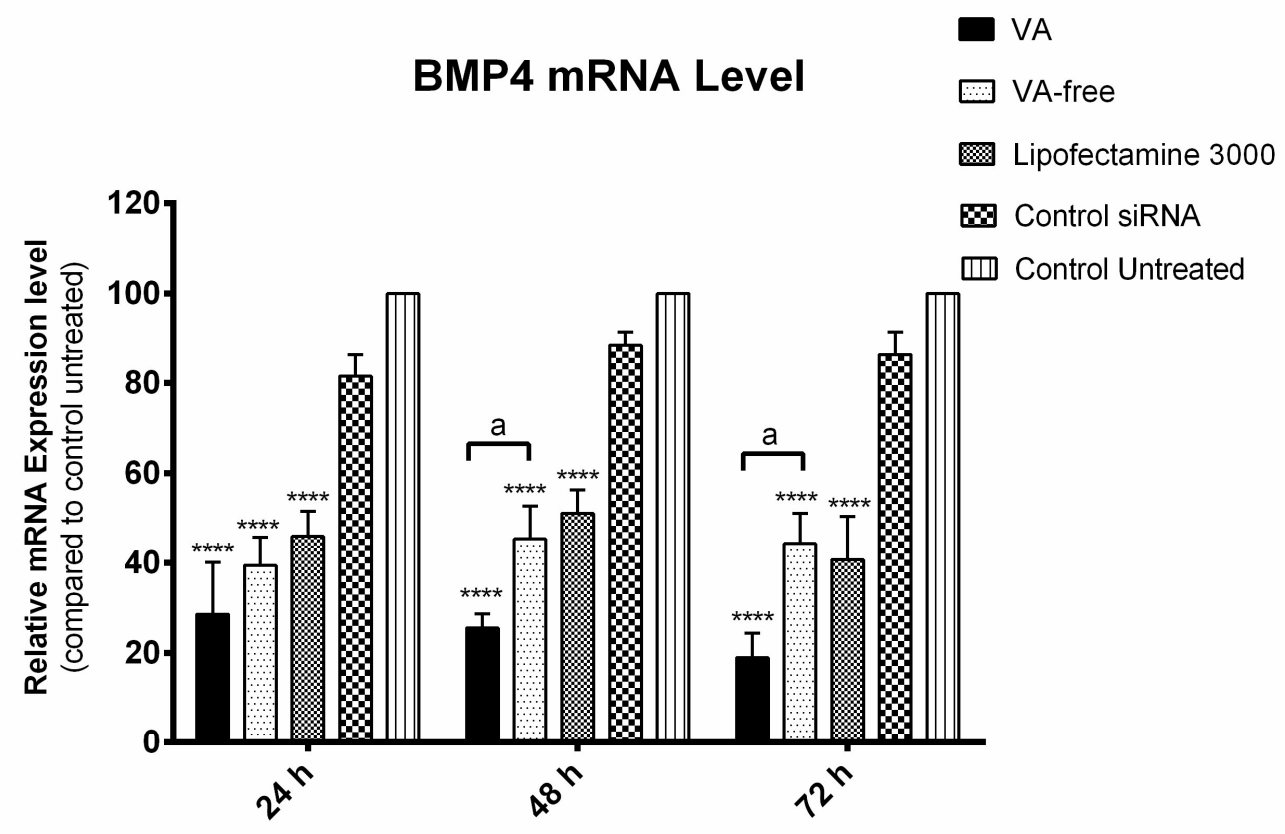

Figure 5. Inhibition of BMP4 in LX-2 cells determined by absolute RT-PCR assay at 24, 48 and $72 \mathrm{hr}$ after treatment with $3 \mu \mathrm{g} / \mathrm{well}$ of BMP4-siRNA using VA-coupled liposomes, VA-free liposomes, Lipofectamine 3000 and Control siRNA. Results were normalized and compared to normal control (non-transfected cells) within same time point, and each value represents the mean \pm S.D. $(\mathrm{n}=3) .{ }^{* * * *}=p<0.0001$ in comparison to the control untreated; a: $p<0.05$

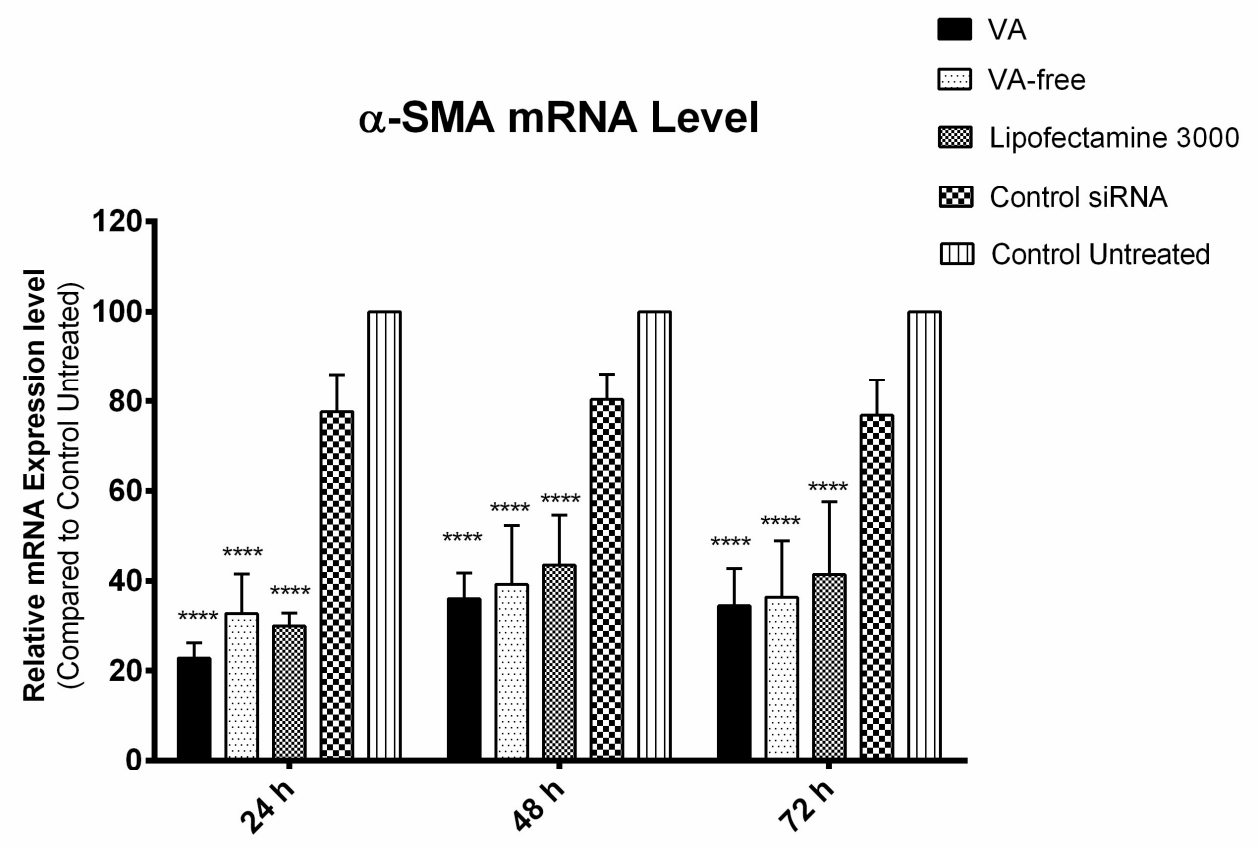

Figure 6. Inhibition of $\alpha$-SMA in LX-2 cells determined by absolute RT-PCR assay at 24,48 and $72 \mathrm{hr}$ after treatment with $3 \mu \mathrm{g} /$ well of BMP4-siRNA using VA-coupled liposomes, VA-free liposomes, Lipofectamine 3000 and Control siRNA. Results were normalized to normal control (non-transfected cells) within same time point. Each value represents the mean \pm S.D. $(\mathrm{n}=3) .{ }^{* * * *}=p<0.0001$ in comparison to the control untreated. 


\section{BMP4 Protein Expression}

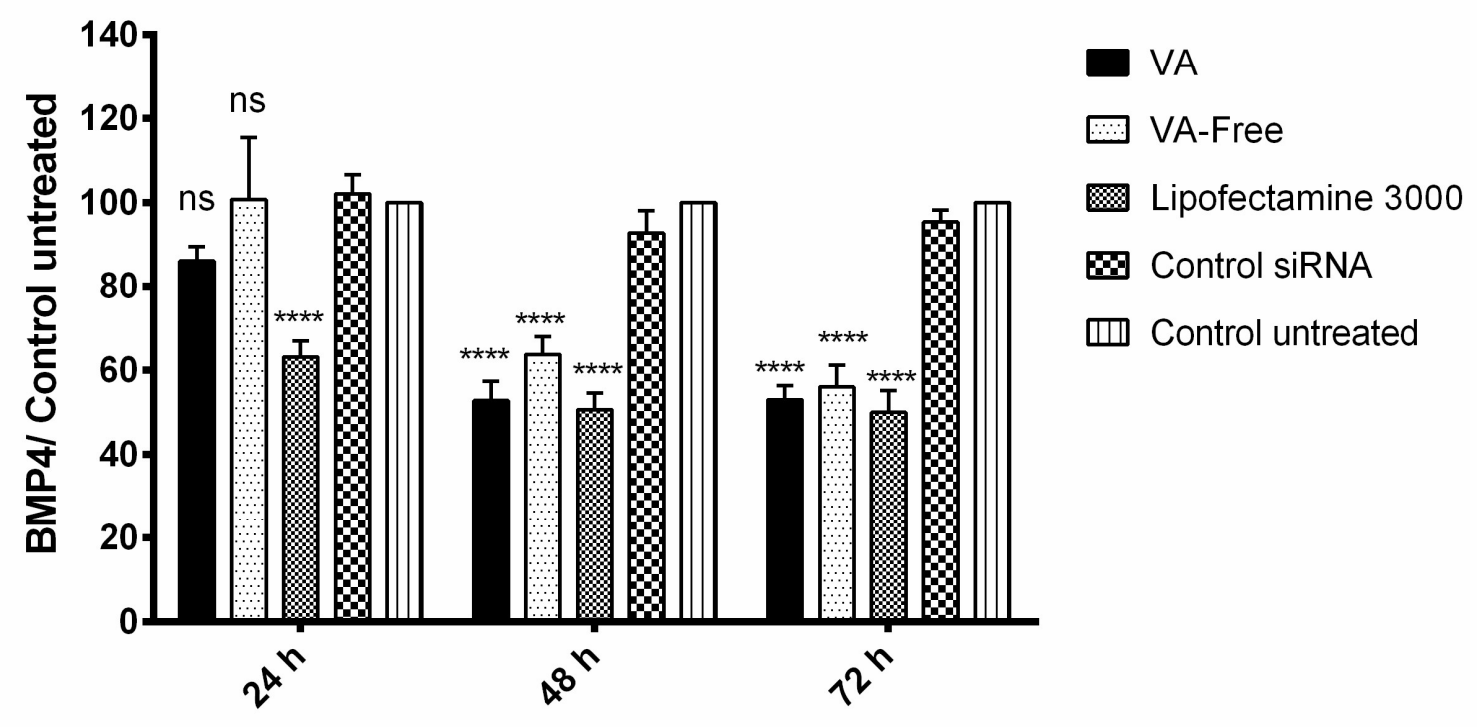

Figure 7. Effect of BMP-4 gene silencing on BMP4 protein expression determined by ELISA at 24, 48 and $72 \mathrm{~h}$ after treatment with $3 \mu \mathrm{g} / \mathrm{well}$ of BMP4-siRNA using VA-coupled liposomes, VA-free liposomes and Lipofectamine 3000. Negative control siRNA was used as internal standard. Results were normalized and compared with normal control (nontransfected cells) within same time point. Each value represents the mean \pm S.D. $(\mathrm{n}=3)$. $)^{* * * *}=p<0.0001$ in comparison to the control untreated.

\section{a-SMA Protein Expression Analysis by ELISA}

To further confirm the effect of BMP4 gene silencing on $\alpha$-SMA protein expression, ELISA was utilized to determine $\alpha$-SMA expression level. The expression profile of $\alpha$-SMA obtained by ELISA was very similar to that of BMP4 (Figure 8). At $24 \mathrm{~h}$ post transfection, both VA-coupled liposomes and VAfree liposomes did not show a significant change in $\alpha$-SMA protein levels. In contrast, Lipofectamine 3000 was shown to knock down the protein expression of $\alpha$-SMA to $72.0 \pm 8.7 \%(p<0.05)$. Conversely, at $48 \mathrm{~h}$ post siRNA transfection the levels of $\alpha$-SMA significantly declined to $63.6 \pm 2.9$ $\%(p<0.01), 50.4 \pm 3.6 \%(p<0.0001)$ and $63.4 \pm$ $10.6 \%(p<0.01)$ following treatment with VAcoupled liposomes, VA-free liposomes, and Lipofectamine 3000, respectively, compared to nontransfected controls. Similarly, at $72 \mathrm{~h}$ post transfection VA-liposomes, VA-free liposomes and Lipofectamine 3000 showed significant suppression of $\alpha$-SMA by $30.9 \pm 7.2 \%(p<0.01), 45.0 \pm 13.8 \%$ $(p<0.001)$ and $32.3 \pm 4.8 \%(p<0.01)$, respectively, compared with non-transfected control. In contrast, there was no significant change in $\alpha$-SMA expression in the group that was treated with control siRNA.

\section{DISCUSSION}

Hepatic fibrosis is a condition that affects millions of people worldwide and has poor prognosis. This is attributed to the fact that fibrosis may progress to cirrhosis, hepatocellular carcinoma, liver failure, and may eventually lead to death (38). HSC are the principal players involved in the pathogenesis of liver fibrosis. $(7,8)$. The reason for the principal involvement of HSC is that liver injury triggers the activation of HSC, which in turn produce large amounts of ECM proteins. Excessive production of ECM proteins results in their accumulation as insoluble substances leading to fibrosis (6). Therefore, targeting HSC is likely an effective strategy for treatment of liver fibrosis (16). 


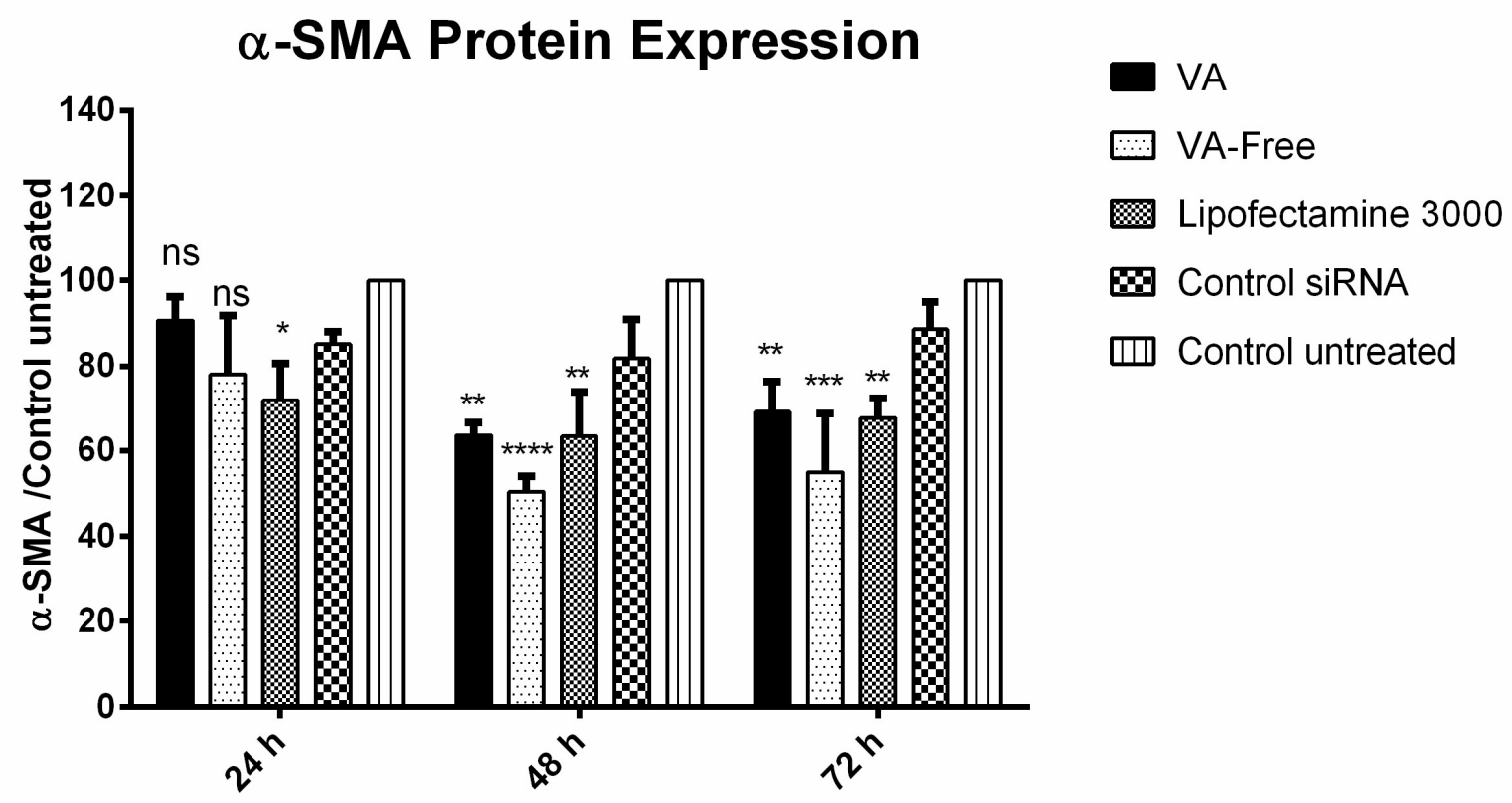

Figure 8. Effect of BMP-4 gene silencing on $\alpha$-SMA protein expression determined by ELISA at 24,48 and 72 hr after treatment with $3 \mu \mathrm{g} /$ well of BMP4-siRNA using VA-coupled liposomes, VA-free liposomes, Lipofectamine 3000 and control siRNA. Results were normalized and compared with normal control (non-transfected cells). Each value represents the mean \pm S.D. $(\mathrm{n}=3) . *=\mathrm{p}$-values $<0.05$ considered significant, $* *=p<0.01$ very significant, $* * *=p<0.001$ highly significant and $* * * *=p<0.0001$ considered very highly significant.

In the present study, VA-coupled liposomes were developed to specifically target HSC with BMP4-siRNA and they were tested in LX-2 cells, an in vitro cell culture model. Particle size was examined to evaluate the effectiveness of size reduction and liposome stability following lyophilization. Particle size is also an important parameter for their entry across cellular membranes by endocytosis. Zeta potential is another important aspect of liposome stability as it reflects the degree of aggregation or repulsion between particles. It is also a critical factor that helps to predict permeability across biological membranes. The change in particle size and zeta potential of particles can alter the transfection efficiency (39).

In order to achieve successful delivery to the hepatic cells, previous studies suggested that the size of nano-therapeutic particles should not exceed 150 $\mathrm{nm}(40,41)$. In addition, it has been reported that nanoparticles between 50 and $200 \mathrm{~nm}$ are not only easily taken up by target cells via passive delivery, but also avoid rapid renal clearance and provide a large surface area that can improve drug release, extend bioavailability, and enhance the biodistribution and efficacy of drugs (42-44).
In the current study, small particle size liposomes $(\sim 110 \mathrm{~nm})$ with uniform size distribution (PDI $\sim 0.20$ ) were obtained after brief sonication of the formulation for $80 \mathrm{sec}$. When liposomes were conjugated to siRNA to form lipoplexes, the average size was increased considerably to $200 \mathrm{~nm}$ and lower with a narrow size distribution that was less than 0.2 . The small PDI of liposomes indicates narrow size distribution (Table 1).

Our data show that the average particle size and zeta potential of VA-coupled liposomes and lipoplexes were barely altered in comparison with their respective VA-free liposomes. The zeta potential values of all liposomes and lipoplexes were positive with a significant decrease after conjugation to siRNA. This decrease in the zeta potential could be due to the neutralization of the cationic lipid head groups (a quaternary amine head group) with anionic phosphate groups of siRNA.

The loading efficiency depends on the strategy used for lipoplexes preparation, lipid/siRNA ratio, and the cationic lipids/neutral lipid ratio (45). In this study, lipoplexes were prepared by a simple adsorption method (external addition). To achieve this, liposomes were first prepared. siRNA was then 
added to the preformed liposomes. The siRNA binding efficiency was calculated by subtracting the free faction measured in the sample from the initial amount of siRNA added. Our results show that siRNA was efficiently associated with cationic liposomes. The binding efficiency of siRNA was assessed using a fixed concentration of the liposomal formulation (30 $\mu \mathrm{g} / \mathrm{mL})$ containing various concentrations of siRNA namely $1,3,5,9 \mu \mathrm{g} / \mathrm{mL}$ and found to be in the range of $90-95 \%$.. This may be due to electrostatic interaction between negatively charged siRNA and positively charged lipids (2123). The data also indicate that siRNA $\mathrm{BE} \%$ of lipoplexes prepared with VA-free liposomes and VA-coupled liposomes remained almost constant, suggesting that the modification of DOPE/DOTAP liposomes with VA had little impact on siRNA BE.

In our cellular uptake study using flow cytometry and spectrofluorimetry, we were able to demonstrate that VA-coupled liposomes achieved significantly higher cellular uptake in comparison with VA-free liposomes. These results were consistent with those from Sato and colleagues (2008) (24) who showed that HSC cells treated with VA-lipsiRNAgp46-FAM demonstrated higher fluorescence in the perinuclear region at $2 \mathrm{hr}$ as compared to faint green fluorescence seen in the perinuclear region of cells treated with lipsiRNAgp46-FAM. There was no significant change in viability of LX-2 cells transfected with VAcoupled liposomes or with VA-free liposomes at the lower lipid concentrations (up to $100 \mu \mathrm{g} / \mathrm{mL}$ ). However, at lipid concentrations $\geq 150 \mu \mathrm{g} / \mathrm{mL}$, cell viability was significantly reduced. These findings suggested that the optimum safe concentration for both VA-coupled liposomes and VA-free liposomes is at $100 \mu \mathrm{g} / \mathrm{mL}$, which shows no toxicity to LX-2 cells ( $\sim 100 \%$ cell viability) (Fig 7$)$. The cell viability findings also led to the conclusion that the amount of VA added to the liposomes was within the safe range as it did not enhance the cytotoxicity of liposomes.

BMP4 is a potent regulator of HSC transdifferentiation and transformation into a myofibroblast-like phenotype (12). Results from the RT-PCR showed that BMP4-siRNA delivered with VA-coupled liposomes reduced BMP4 mRNA by $\sim 75 \%$ compared to untreated control, while treatment with BMP4-siRNA/ VA-free liposomes resulted in $\sim 55 \%$ knockdown of BMP4 mRNA. Since BMP4 regulates HSC trans-differentiation and transformation into myofibroblast-like phenotype through controlling the activity of $\alpha$-SMA, BMP4siRNA inhibited $\alpha$-SMA expression at the same level as it did for BMP4. This result is consistent with previously published data implicating that the expression of $\alpha$-SMA is increased in HSC after treatment with BMP4 (12). In addition, ELISA results showed that BMP4-siRNA caused significant reduction in BMP4 and $\alpha$-SMA protein levels at 48 $\mathrm{h}$ and $72 \mathrm{hr}$ post transfection approaching $\sim 50 \%$ in the protein expression of both BMP4 and $\alpha$-SMA. However, there was nearly no effect on both BMP4 and $\alpha$-SMA protein expression after $24 \mathrm{hr}$ post treatment with BMP4-siRNA.

Generally, the duration and level of gene silencing resulting from siRNA are dependent on the type of cell, concentration of siRNA and size of protein. This effect usually lasts from five to seven days $(46,47)$. Therefore, transfections may be repeated to maintain knockdown. Because siRNA only suppresses the expression of newly transcribed mRNA, it is possible that the observed level may be either due to the residual protein expressed by cell prior to siRNA treatment or due to the mRNA that was not successfully transfected (48). The unsuccessful or incomplete capacity to silence the target gene expression could be to the failure of liposome to deliver siRNA, or due to siRNA degradation. The reasons mentioned above may explain why BMP4-siRNA could not down regulate the protein expression after $24 \mathrm{hr}$ and why $100 \%$ protein knockdown at 48 and $72 \mathrm{hr}$ post treatment was not achieved. Taken together, the results may imply that the anti-fibrotic properties of BMP4siRNA occur via inhibition of the $\alpha$-SMA.

\section{CONCLUSION}

This study focused on targeting HSC through inhibiting BMP4 using siRNA. Cationic DOPE/DOTAP liposomes modified with VA were successfully developed for the targeted delivery of siRNA. Liposomes were optimized to result in a favorable particle size $(\sim 110 \mathrm{~nm})$ and to maximize siRNA loading efficiency. The efficacy of the formulation was tested in an in vitro cell culture model. Inclusion of VA in the cationic liposomes significantly improved the cellular uptake without affecting the cytotoxicity allowing a significant reduction both BMP4 and $\alpha$-SMA at both mRNA\& protein level. This approach may provide a successful tool to target HSC and resolve fibrosis. 
Additional studies in different models of liver fibrosis are required to optimize the efficacy and safety of the delivery system. In vivo studies are also warranted to further confirm findings and estimate therapeutic doses.

\section{ACKNOWLEDGEMENT}

The research was supported by a grant from the Natural Science and Engineering Research Council (NSERC) to Professor Yuewen Gong.

\section{REFERENCES}

1. Lee UE, Friedman SL. Mechanisms of hepatic fibrogenesis. Best practice \& research Clinical gastroenterology. 2011;25(2):195-206.

2. Li JT, Liao ZX, Ping J, Xu D, Wang H. Molecular mechanism of hepatic stellate cell activation and antifibrotic therapeutic strategies. Journal of gastroenterology. 2008;43(6):419-28.

3. Adrian JE, Poelstra K, Kamps JA. Addressing liver fibrosis with liposomes targeted to hepatic stellate cells. Journal of liposome research. 2007;17(34):205-18.

4. Lee UE, Friedman SL. Mechanisms of hepatic fibrogenesis. Best Practice \& Research Clinical Gastroenterology. 2011;25(2):195-206.

5. Friedman SL. Liver fibrosis -- from bench to bedside. Journal of hepatology. 2003;38 Suppl 1:S38-53.

6. Hui AY, Friedman SL. Molecular basis of hepatic fibrosis. Expert reviews in molecular medicine. 2003;5(5):1-23.

7. Maher JJ, McGuire RF. Extracellular matrix gene expression increases preferentially in rat lipocytes and sinusoidal endothelial cells during hepatic fibrosis in vivo. The Journal of clinical investigation. 1990;86(5):1641-8.

8. Wu J, Zern MA. Hepatic stellate cells: a target for the treatment of liver fibrosis. Journal of gastroenterology. 2000;35(9):665-72.

9. Friedman SL. Mechanisms of disease: Mechanisms of hepatic fibrosis and therapeutic implications. Nature clinical practice Gastroenterology \& hepatology. 2004;1(2):98-105.

10. Alcolado R, Arthur MJ, Iredale JP. Pathogenesis of liver fibrosis. Clinical science (London, England : 1979). 1997;92(2):103-12.

11. Bataller R, Brenner DA. Liver fibrosis. The Journal of clinical investigation. 2005;115(2):209-18.

12. Shen H, Huang GJ, Gong YW. Effect of transforming growth factor beta and bone morphogenetic proteins on rat hepatic stellate cell proliferation and transdifferentiation. World journal of gastroenterology : WJG. 2003;9(4):784-7.
13. Fan J, Shen H, Sun Y, Li P, Burczynski F, Namaka $\mathrm{M}$, et al. Bone morphogenetic protein 4 mediates bile duct ligation induced liver fibrosis through activation of Smad1 and ERK1/2 in rat hepatic stellate cells. Journal of cellular physiology. 2006;207(2):499-505.

14. Chiu CY, Kuo KK, Kuo TL, Lee KT, Cheng KH. The activation of MEK/ERK signaling pathway by bone morphogenetic protein 4 to increase hepatocellular carcinoma cell proliferation and migration. Molecular cancer research : MCR. 2012;10(3):415-27.

15. Maegdefrau U, Amann T, Winklmeier A, Braig S, Schubert T, Weiss TS, et al. Bone morphogenetic protein 4 is induced in hepatocellular carcinoma by hypoxia and promotes tumour progression. The Journal of pathology. 2009;218(4):520-9.

16. Narmada BC, Kang Y, Venkatraman L, Peng Q, Sakban RB, Nugraha B, et al. Hepatic stellate celltargeted delivery of hepatocyte growth factor transgene via bile duct infusion enhances its expression at fibrotic foci to regress dimethylnitrosamine-induced liver fibrosis. Human gene therapy. 2013;24(5):508-19.

17. Kim DH, Rossi JJ. Overview of gene silencing by RNA interference. Current protocols in nucleic acid chemistry / edited by Serge L Beaucage [et al]. 2009; Chapter 16:Unit 16.1.

18. de Fougerolles A, Vornlocher HP, Maraganore J, Lieberman J. Interfering with disease: a progress report on siRNA-based therapeutics. Nature reviews Drug discovery. 2007;6(6):443-53.

19. Whitehead KA, Langer R, Anderson DG. Knocking down barriers: advances in siRNA delivery. Nature reviews Drug discovery. 2009;8(2):129-38.

20. de Fougerolles AR. Delivery vehicles for small interfering RNA in vivo. Human gene therapy. 2008;19(2):125-32.

21. Verma UN, Surabhi RM, Schmaltieg A, Becerra C, Gaynor RB. Small interfering RNAs directed against beta-catenin inhibit the in vitro and in vivo growth of colon cancer cells. Clinical cancer research : an official journal of the American Association for Cancer Research. 2003;9(4):1291-300.

22. Kesharwani P, Gajbhiye V, Jain NK. A review of nanocarriers for the delivery of small interfering RNA. Biomaterials. 2012;33(29):7138-50.

23. Gomes-da-Silva LC, Fonseca NA, Moura V, Pedroso de Lima MC, Simoes S, Moreira JN. Lipid-based nanoparticles for siRNA delivery in cancer therapy: paradigms and challenges. Accounts of chemical research. 2012;45(7):1163-71.

24. Sato Y, Murase K, Kato J, Kobune M, Sato T, Kawano Y, et al. Resolution of liver cirrhosis using vitamin A-coupled liposomes to deliver siRNA against a collagen-specific chaperone. Nature biotechnology. 2008;26(4):431-42.

25. Bangham AD, De Gier J, Greville GD. Osmotic properties and water permeability of phospholipid 
liquid crystals. Chemistry and Physics of Lipids. 1967;1(3):225-46.

26. Chaudhury A, Das S, Lee RF, Tan KB, Ng WK, Tan $\mathrm{RB}$, et al. Lyophilization of cholesterol-free PEGylated liposomes and its impact on drug loading by passive equilibration. International journal of pharmaceutics. 2012;430(1-2):167-75.

27. Kundu AK, Chandra PK, Hazari S, Ledet G, Pramar YV, Dash S, et al. Stability of lyophilized siRNA nanosome formulations. International journal of pharmaceutics. 2012;423(2):525-34.

28. Chen C, Han D, Cai C, Tang X. An overview of liposome lyophilization and its future potential. Journal of controlled release : official journal of the Controlled Release Society. 2010;142(3):299-311.

29. Allison SD, Anchordoquy TJ. Mechanisms of protection of cationic lipid-DNA complexes during lyophilization. Journal of pharmaceutical sciences. 2000;89(5):682-91.

30. Allison SD, Molina MC, Anchordoquy TJ. Stabilization of lipid/DNA complexes during the freezing step of the lyophilization process: the particle isolation hypothesis. Biochimica et biophysica acta. 2000;1468(1-2):127-38.

31. Ozaki K, Hayashi M. The effects of glucose oligomers (maltodextrins) on freeze-drying liposomes. Chemical \& pharmaceutical bulletin. 1997;45(1):165-70.

32. Taetz S, Bochot A, Surace C, Arpicco S, Renoir JM, Schaefer UF, et al. Hyaluronic acid-modified DOTAP/DOPE liposomes for the targeted delivery of anti-telomerase siRNA to CD44-expressing lung cancer cells. Oligonucleotides. 2009;19(2):103-16.

33. Gao J, Yu Y, Zhang Y, Song J, Chen H, Li W, et al. EGFR-specific PEGylated immunoliposomes for active siRNA delivery in hepatocellular carcinoma. Biomaterials. 2012;33(1):270-82.

34. Gilleron J, Querbes W, Zeigerer A, Borodovsky A, Marsico G, Schubert U, et al. Image-based analysis of lipid nanoparticle-mediated siRNA delivery, intracellular trafficking and endosomal escape. Nature biotechnology. 2013;31(7):638-46.

35. Genestar C, Grases F. Determination of vitamin A in pharmaceutical preparations by high-performance liquid chromatography with diode-array detection. Chromatographia. 1995;40(3-4):143-6.

36. Tian Q, Zhang CN, Wang XH, Wang W, Huang W, Cha RT, et al. Glycyrrhetinic acid-modified chitosan/poly(ethylene glycol) nanoparticles for liver-targeted delivery. Biomaterials. 2010;31(17):4748-56.

37. Li SD, Huang L. Targeted delivery of antisense oligodeoxynucleotide and small interference RNA into lung cancer cells. Molecular pharmaceutics. 2006;3(5):579-88.

38. Bhala N, Jouness RI, Bugianesi E. Epidemiology and natural history of patients with NAFLD. Current pharmaceutical design. 2013;19(29):5169-76.

39. Romoren K, Aaberge A, Smistad G, Thu BJ, Evensen O. Long-term stability of chitosan-based polyplexes. Pharmaceutical research. 2004;21(12):2340-6.

40. Fumoto S, Nakadori F, Kawakami S, Nishikawa M, Yamashita F, Hashida M. Analysis of hepatic disposition of galactosylated cationic liposome/plasmid DNA complexes in perfused rat liver. Pharmaceutical research. 2003;20(9):1452-9.

41. Higuchi Y, Kawakami S, Fumoto S, Yamashita F, Hashida M. Effect of the particle size of galactosylated lipoplex on hepatocyte-selective gene transfection after intraportal administration. Biological \& pharmaceutical bulletin. 2006;29(7):1521-3.

42. Zhang L, Gu FX, Chan JM, Wang AZ, Langer RS, Farokhzad OC. Nanoparticles in medicine: therapeutic applications and developments. Clinical pharmacology and therapeutics. 2008;83(5):761-9.

43. Petros RA, DeSimone JM. Strategies in the design of nanoparticles for therapeutic applications. Nature reviews Drug discovery. 2010;9(8):615-27.

44. Tiram G, Scomparin A, Ofek P, Satchi-Fainaro R. Interfering cancer with polymeric siRNA nanomedicines. Journal of biomedical nanotechnology. 2014;10(1):50-66.

45. Maitani Y. Lipoplex formation using liposomes prepared by ethanol injection. Methods in molecular biology (Clifton, NJ). 2010;605:393-403.

46. Bartlett DW, Davis ME. Insights into the kinetics of siRNA-mediated gene silencing from live-cell and live-animal bioluminescent imaging. Nucleic acids research. 2006;34(1):322-33.

47. Leng Q, Woodle MC, Lu PY, Mixson AJ. Advances in Systemic siRNA Delivery. Drugs of the future. 2009;34(9):721.

48. Zhou D, He QS, Wang C, Zhang J, Wong-Staal F. RNA interference and potential applications. Current topics in medicinal chemistry. 2006;6(9):901-11. 


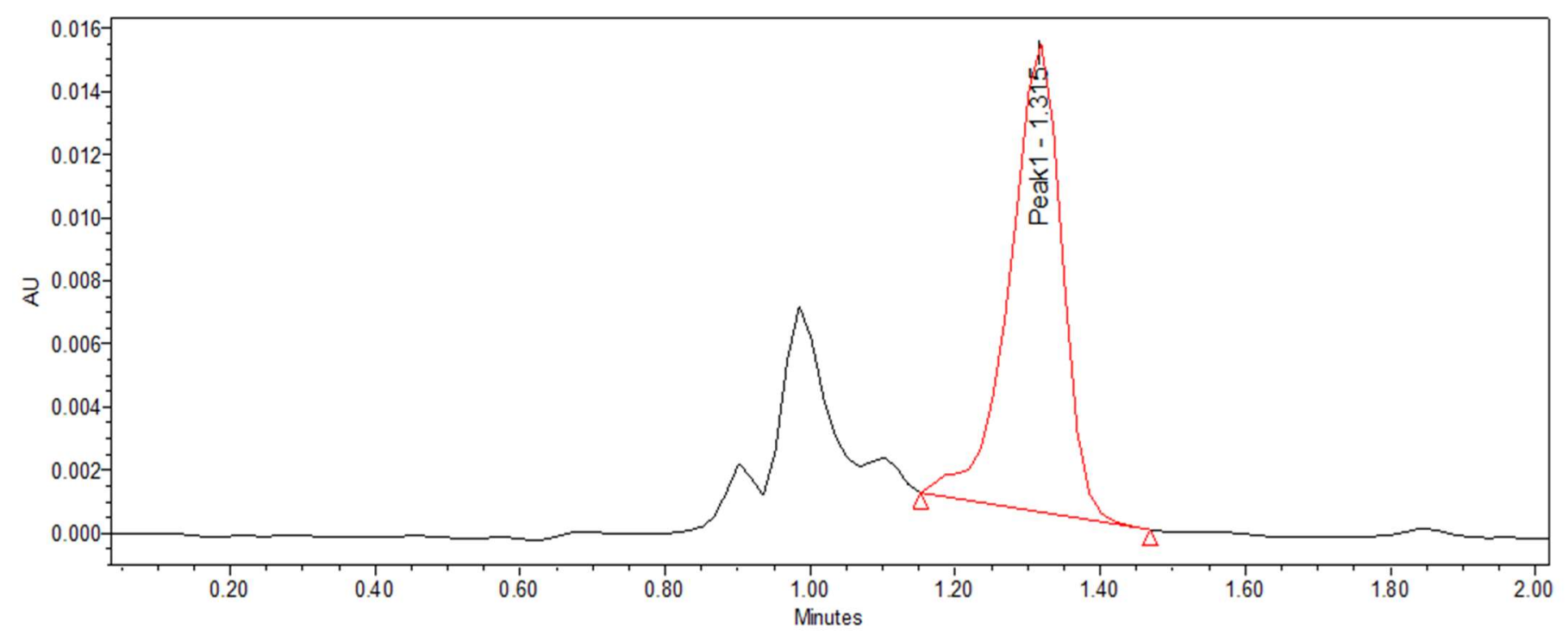

Sup figure 1: Representative chromatogram of retinol (VA) spiked in the mobile phase. 